\title{
Foraging Behavior of Apis mellifera in Southwestern Ohio during the Late Summer Months
}

\author{
JULIA HONCHEL and SAVITHA KRISHNA', Department of Biology, Wilmington College, Wilmington, OH, USA
}

\begin{abstract}
Honey bees (Apis mellifera L.) depend on floral resource availability, and landscape composition has been recognized as a critical determinant of honey bee colony success. Knowledge of honey bee foraging behavior and diurnal activity patterns are important parameters that can be used to inform the landscape design and floral compositions for establishing sustainable honey bee colonies in small-scale farms. However, relatively little is known about foraging behavior of regional honey bees in Ohio. This study was conducted in August-September 2014, to understand the foraging behavior of Apis mellifera L. in Yellow Springs, Ohio $\left(39.7993^{\circ} \mathrm{N}, 83.8877^{\circ} \mathrm{W}\right)$. We found that more foragers brought nectar than pollen during our study period. The result suggests that the foraging rate was highest in the afternoon, from 1240 to $1500 \mathrm{~h}$ followed by evenings, from 1800 to $1900 \mathrm{~h}$ and least in the morning, from 0700 to $1000 \mathrm{~h}$. There was a significant positive correlation between the foraging activities of the honey bees and the daily temperature. Highest foraging activity was recorded for the day with average temperature of $27^{\circ} \mathrm{C}$ and lowest for $13^{\circ} \mathrm{C}$ and none below $13^{\circ} \mathrm{C}$. Our quantitative data provides a baseline for future monitoring of colony growth and evaluation of floral composition of pollinator pathways that support the sustainable apiculture in small-scale farmlands in southwestern Ohio.
\end{abstract}

OHIO J SCI 116(2):21-25

\section{INTRODUCTION}

The honey bee, Apis mellifera L., is a part of a highly organized society. Bees communicate with one another to ensure homeostasis, overall health and fitness of the beehive. Within one colony, there can be up to 60,000 sterile female worker bees, several hundred male drones, and one queen. The drones fertilize the queen, the queen lays the eggs (nearly 1,500 a day) and the worker bees feed and take care of the brood. Additionally, worker bees clean the hive, forage for food, store food, and tend to the larvae and the queen (Bishop 2005). In the colony, 25 percent of adult bees are foragers (Dreller et al. 1999) and 20 percent of adult bees store food (Seeley 1989). Honey bee workers typically start brood care during the first two to three weeks of adult life span and then become foragers (Toth et al. 2005). Brood rearing labor is divided among workforce. For example, some individuals work outside as foragers and others are inside cleaning and maintaining the nest. Individual foraging workers will specialize in collecting nectar or pollen or both (Pankiw et al.1998).

Nectar evaporates into honey, which not only fuels the worker bees for flights, but also heats the hive and stocks the hive for the winter. Typically, bees will

\footnotetext{
${ }^{1}$ Address correspondence to Savitha Krishna, Department of Biology, Wilmington College, Wilmington, OH 45177. E-mail: savitha_krishna@wilmington.edu
}

collect more nectar than is actually needed to sustain the hive during cold weather. For example, one hive might produce nearly $60 \mathrm{~kg}$ of honey and consume only $35 \mathrm{~kg}$ in a year. On the other hand, bees collect and store just enough pollen for the colony. Pollen is the protein source primarily for larvae but also for the entire colony. They will collect about $20 \mathrm{~kg}$ of pollen, and stockpile only about $1 \mathrm{~kg}$ (Camazine 1992).

Foraging behavior in honey bees is determined by a variety of factors. Nectar foragers gather information from their nest mates about the nectar supply within the hive (Dreller et al. 1999). They determine the nutritional status of the hive by the availability of food-storers to transfer their nectar and then adjust the quality of nectar they bring back, according to the needs of the colony (Seeley 1989). Pollen foragers, on the other hand, determine the needs of pollen in the hive by identifying the amount of brood pheromone (an indicator of numbers of progeny), the amount of pollen already stored in the hive, the space available for more pollen stores, and available resources in the environment (Pankiw et al. 1998).

In the late summer and early fall, the colony needs to start preparing for colder temperatures. As nectar and pollen sources decrease, the queen begins laying fewer eggs and the colony begins pushing the drones out of the hive in order to preserve food. As the temperature drops, bees begin huddling together to keep warm. The health of the colony in autumn will 
influence its winter survival, and how it will fare the next year (Seeley and Visscher 1985).

Honey bees are the most economically-valuable pollinators of agricultural crops worldwide. In the U.S. alone, the value of agricultural crops pollinated by bees each year is more than $\$ 17$ billion (Calderone 2012). The beekeepers' survey of managed honey bee colonies found overall losses of 33 percent reported in 2010 and 22 percent on average during winter 2012. Even though it is clear that the number of managed colonies in the U.S. has declined over the years since 2006 colony collapse disorder reports (Ellis et al. 2010), state and regional economic data on honey bee production remains anecdotal. Nevertheless, the overall proportion of winter losses is high, and the continued economic viability of pollination by honey bees remains threatened (USDA 2012). Understanding factors of honey bee colony behavior may provide insights for managing and sustaining honey bee populations in the future.

Relatively little is known about the honey bee foraging behavior in Ohio. We observed the foraging behavior of a colony of bees in the rural area of Yellow Springs, Ohio during the late summer/early fall of 2014. Our objective was to establish baseline foraging behavior to aid in establishing long-term monitoring programs for planning pollinator pathways as part of sustainable farm expansion in the wake of regional and global apiculture decline (Neumann and Carreck 2010; vanEngelsdorp et al. 2011; Rinkevich et al. 2015).

\section{METHODS}

Between 25 August 2014 and 18 September 2014, honey bee foraging behavior of a colony in a Langstroth hive at Yellow Springs, Ohio $\left(39.7993^{\circ} \mathrm{N}, 83.8877^{\circ}\right.$ W) was observed on 10 different days. Observation days were selected based on consistent weather patterns, favoring sunny and warm weather representing late summer in southwestern Ohio. Nectar and pollen foraging behavior was recorded daily for 45 minutes, 15 minutes in the morning $(0800 \mathrm{~h})$, afternoon (1230 $\mathrm{h})$, and evening (1900 h).

We recorded the number of bees returning to the hive with pollen and nectar. Foragers returning to the hive without pollen with abdomens distended were counted as mostly likely with nectar (Huang et al. 1994). Pollen was visible in the pollen sacs on the legs of the bees. We collected data on the number of bees cleaning or fanning the hive entrance, daily temperature and the weather data (cloudy, humid, clear sky or rainy) and any identifiable variation in the bee behavior. Average daily temperature ranges (minimum-maximum) was gathered from the NOAA ("Daily Climate Report"). Data was pooled and averages were calculated from all the observations $(\mathrm{N}=30)$. We used student $\mathrm{t}$-test and ANOVA to analyze our data.

\section{RESULTS}

A total of 12,327 returning bees were observed for foraging activity during the study period. Foragers brought either nectar or pollen with a significantly higher number of bees carrying nectars $(\bar{X}=20.1 \pm$ 8.3 per min) than the pollen $(\overline{\mathrm{X}}=7.3 \pm 4.5$ bees per min; $\mathrm{P}<0.01$; Fig. 1). However, we did not find a statistically-significant relationship between the time of the day (morning, afternoon and evening) and the preference for nectar or pollen $\left(\mathrm{F}_{(2,10)}=2.55 ; \mathrm{P}=0.15\right)$. Honey bee activity patterns fluctuated throughout the day. Foraging activity was highest between 1240 to 1500 $\mathrm{h}(\overline{\mathrm{X}}=18.77 \pm 3.95$ per minute, $\mathrm{P}<0.01)$ followed by 1800 to $1900 \mathrm{~h}(\overline{\mathrm{X}}=10.85 \pm 3.79$ per minute, $\mathrm{P}<$ $0.01)$ and least in the morning, between 0700 to 1000 $\mathrm{h}(\overline{\mathrm{X}}=3.46 \pm 2.45$ per minute, $\mathrm{P}<0.01)$.

The temperature decreased fairly steadily from $26^{\circ} \mathrm{C}$ on the first day to $16^{\circ} \mathrm{C}$ on the last day of our observation (Fig. 2). There was a significant positive correlation between the foraging activities of the honey bees and the daily temperature $\left(\mathrm{r}^{2}=0.63, \mathrm{df}=9, \mathrm{P}<\right.$ $0.01)$. Highest foraging activity was recorded for the day with average temperature of $27^{\circ} \mathrm{C}$ and lowest for $13^{\circ} \mathrm{C}$.

The cleaning of the hive entrance also decreased over time as the average daily temperature started declining (Fig. 3). On the days when the ambient temperature ranged $25^{\circ} \mathrm{C}-27^{\circ} \mathrm{C}$ we recorded some cleaning activity at the hive entry $(\bar{X}=2.71 \pm 1.24$ bees per minute $)$.

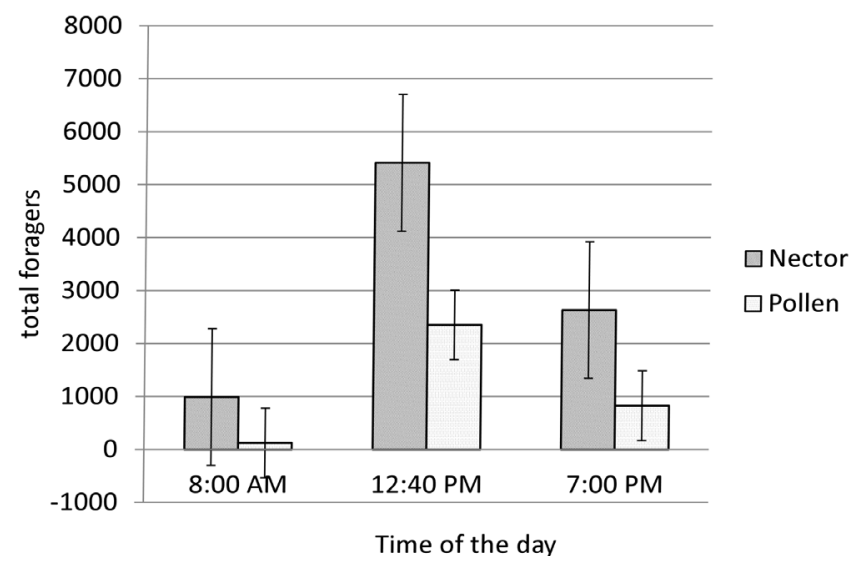

Figure 1. Diurnal foraging pattern of the honey bees (Apis mellifera L.) in Yellow Springs, Ohio $\left(39.7993^{\circ} \mathrm{N}, 83.8877^{\circ} \mathrm{W}\right)$ during the study period (Aug-Sep 2014). 
However, when the temperature dropped below $21^{\circ} \mathrm{C}$ very few workers cleaned the hive $(\bar{X}=0.38 \pm 0.02$ bees per minute) and below $16^{\circ} \mathrm{C}$ there was no foraging or cleaning activity. There was positive correlation between the cleaning activity and ambient diurnal temperature $\left(\mathrm{r}^{2}=0.36, \mathrm{df}=9, \mathrm{P}<0.05\right)$

\section{DISCUSSION}

Many studies examining the Apis mellifera L. foraging activity indicate the species is known to begin foraging in the early morning (Joshi and Joshi 2010; AbouShaara 2014). Tan et al. (2012) had reported highest activity for $A$. mellifera L. at ambient temperatures of about $20^{\circ} \mathrm{C}$. While the species showed lowest foraging activity at $43^{\circ} \mathrm{C}$ (Blazyte-Cereskiene et al.2010) and at or below $10^{\circ} \mathrm{C}$ (Joshi and Joshi 2010). Other studies have identified a negative correlation between foraging activity and temperature (Abou-Shaara et al. 2013). It is possible that foraging decreases could be related to a range of factors including colder temperatures, contributing to a greater need for bees to be inside the hive to stay warm, diminishing nectar and pollen resources, or less of a demand for food due to slower brood production.

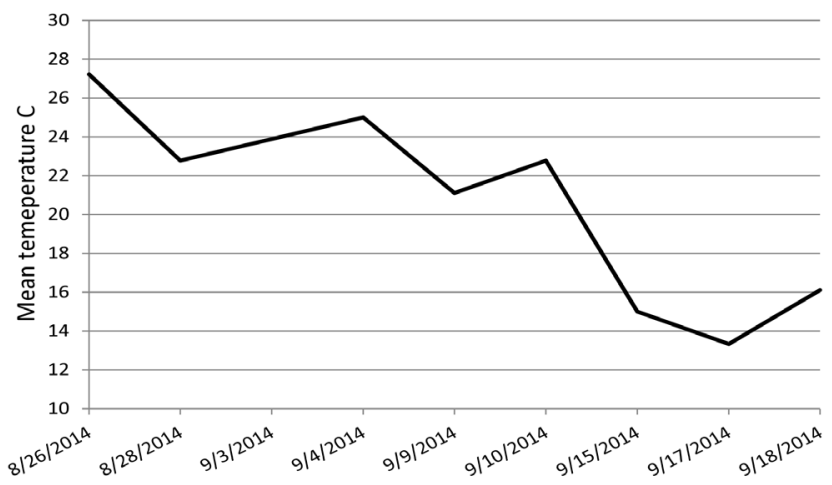

Figure 2. Mean daily temperature in Yellow Springs, Ohio during the study period (Aug-Sep 2014).

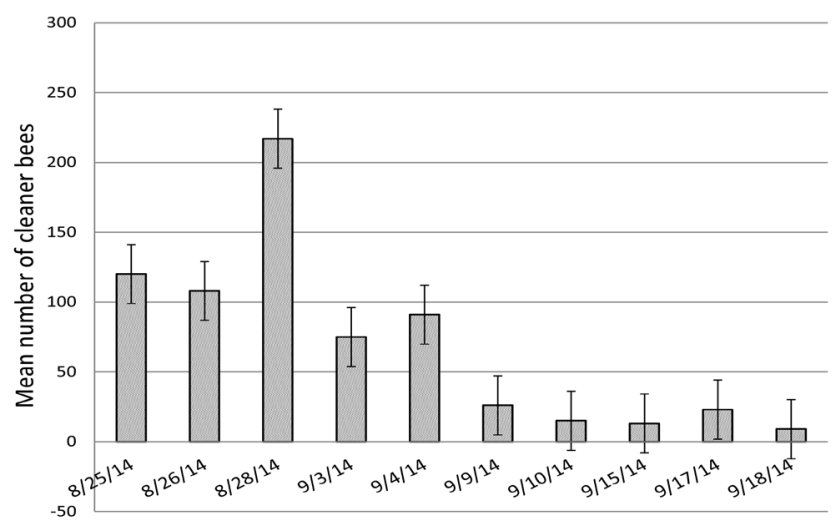

Figure 3. Hive entrance-cleaning pattern of honey bees (Apis mellifera L.) colony at Yellow Springs, Ohio during the study period (Aug-Sep 2014).
Our results indicate highest foraging activity when the diurnal ambient temperature was $27^{\circ} \mathrm{C}$ and lowest for $13^{\circ} \mathrm{C}$. Although we noticed bee activity began at approximately $0700 \mathrm{~h}$, the majority of bees did not return to the hive with either nectar or pollen until $0800 \mathrm{~h}$. We found fluctuations in the bee activity similar to the observations by Pernal and Currie (2010) in Manitoba, Canada. The species have peak activity in the afternoon between 1300 to $1500 \mathrm{~h}$ and decline steadily (Joshi and Joshi 2010). They are least active in the morning hours (Pudasaini and Thapa 2014). Our results were similar to previous studies in that we recorded higher mean foraging rates in the afternoon (18.8 foragers/minute) than evening (10.9 foragers/ minute) and observed the least activity during the morning (3.5 foragers/minute) hours. These results may be indicative of bee physiology, resource availability throughout the day and ideal out-colony conditions for foraging. Morning dew and cool temperatures during this time of day might inhibit bee activity while afternoon temperatures and sunny conditions might encourage activity.

Several in-colony factors and out-colony factors can affect food preference and foraging activity (AbouShaara 2014). Higher foraging activity with less pollen collection has been noted in colonies headed by virgin queens than colonies with mated queens. Ovariole number, pheromones and genotype of honey beestrains are known to strongly influence the foraging behavior for nectar or for pollen (Siegel et al. 2012; Pankiw et al. 2002). Our results suggest that more bees collected nectar rather than pollen in the study area $(\bar{X}=20 \pm$ 8.3 vs. $\bar{X}=7.3 \pm 4.5$ ) which be indicative of multiple factors. For example, the out-colony factors such as plant resource availability around in the vicinity of the hives may affect their foraging behavior. Pollen production increases when there is brood rearing and a decreased storage of pollen in the hive as well as available pollen resources outside the hive (Pankiw et al. 1998). In Ohio, food accumulation and wax production increase with surrounding cropland and decrease with forest and grassland. The productivity of honey depends on cooperative foraging on landscape composition including weeds such as non-native clovers (Trifolium spp. L.), and agricultural crops such as soybean (Sponsler and Johnson 2015). Furthermore, recent work by Richardson et al. (2015) in Madison County, Ohio, indicates that the bulk of the pollens come from trees (Sapindaceae, Oleaceae, and Rosaceae), dandelions (Taraxacum officinale) and mustard 
(Brassicaceae). Our beehive was located at the border of a small farm that was surrounded by weeds and a vegetable garden. This suggests that the resources were available to account for higher nectar foraging by bees.

Astudy by Fewell and Winston (1992) reported that when pollen storage was low, pollen intake increased by 54 percent relative to high pollen storage conditions. They found that nearly 80 percent of the increase came from individual changes in foraging activity and pollen load size, while only 20 percent of the increase came from a change in the proportion of foraging population collecting pollen. Bees appear to alter their behavior until the pollen storage reaches homeostatic set-point (Weidenmüller and Tautz 2002). In this study, it is possible that reduced pollen collection was due to adequate pollen in the hive so that pollen foragers transitioned to nectar foragers during that time.

Honey bee workers display age-based division of labor and young bees are known to perform in-hive tasks before they transition out as foragers (Rueppell et al. 2007). As the ambient temperature began to decline, the cleaners outside the hive reduced their activity. Similar to the report by Joshi and Joshi (2010) below $16^{\circ} \mathrm{C}$ we noticed no flight or cleaning activity. This probably indicates that a greater number of bees are needed inside the hive to keep warm, or that the hive is no longer so hot that bees had to move outside to keep the hive cool.

Bees pollinate about 130 agricultural plant species in the U.S. Bees pollinate 63 (77 percent) out of 82 commodity crops of the world's flowering plant species including soybean and sunflower, 400 of the world's agricultural plants (Delaplane and Mayer 2000). In turn, flowers provide nectar and pollen to produce honey and wax.

It is unclear if the diurnal activity patterns and behavior we observed is specific to the season or to the context of this hive alone. Further research that monitors the multiple colonies over the longer term would be useful to understand the effect of landscape changes on their behavior beyond this study.

\section{ACKNOWLEDGMENTS}

We thank reviewers for their valuable comments on the initial manuscript. We also thank Wilmington College, Ohio for their academic support. This research was supported by Antioch College farm, Yellow Springs, Ohio.

\section{LITERATURE CITED}

Abou-Shaara HF. 2014. The foraging behaviour of honey bees, Apis mellifera: a review Veterinarni Medicina. 59:1-10

Bishop H. 2005. Robbing the bees: a biography of honey, the sweet liquid gold that seduced the world. New York, NY: Free Press. 326 pages

Blazyte-Cereskiene L, Vaitkeviciene G, Venskutonyte S, Buda V. 2010. Honey bee foraging in spring oilseed rape crops under high ambient temperature conditions. ZemdirbysteAgriculture. 97:61-70.

Calderone NW. 2012. Insect pollinated crops, insect pollinators and US agriculture: Trend analysis of aggregate data for the period 1992-2009. PLoS One 7: e37235. doi: 10.1371/ journal.pone.0037235

Camazine S. 1992. The regulation of pollen foraging by honey bees: how foragers assess the colony's need for pollen. Behav EcolSociobiol. 32:265-272.

Delaplane KS, Mayer DF. 2000. Crop Pollination by Bees. Wallingford, England: CABI publishing. 352 pages.

"Daily Climate Report." NOAA: National Weather Service Forecast Office. Accessed 24 Sept. 2014. < http://www.nws. noa.gov/climate/index.php?wfo=iln>

Dreller C, Page Jr RE, Fondrk MK. 1999. Regulation of pollen foraging in honey bee colonies: effects of young brood, stored pollen, and empty space. Behav EcolSociobiol. 45:227-233.

Ellis, J. D., Evans, J. D., \& Pettis, J. 2010. Colony losses, managed colony population decline, and colony collapse disorder in the United States. J Apicult Res, 49(1), 134-136. doi:10.3896/ IBRA.1.49.1.30

Fewell JH, Winston ML. 1992. Colony state and regulation of pollen foraging in the honey bee Apismellifera L. BehavEcol Sociobiol. 30:387-393

Huang ZY, Robinson GE, Borst DW. 1994. Physiological correlates of division of labor among similarly aged honey bees. J Comp Physiol A. 174:731-9.

Joshi NC, Joshi PC. 2010. Foraging behaviour of Apis Spp. on apple flowers in a subtropical environment. NYSci J. 3:71-76

Neumann P, Carreck NL. 2010. Honey bee colony losses. J Apicult Res. 49:1-6.

Pernal SF, Currie, RW. 2010. The influence of pollen quality on foraging behavior in honeybees (Apis mellifera L.). Behav Ecol Sociobiol. 51:53-68. DOI 10.1007/s002650100412

Pankiw T, Page Jr RE, Fondrk MK. 1998. Brood pheromone stimulates pollen foraging in honey bees (Apis mellifera). Behav Ecol and Sociobiol. 44:193-198.

Pankiw T, Tarpy DR, Page RE. 2002. Genotype and rearing environment affect honeybee perception and foraging behaviour. Anim Behav 64, 663-672.

Pudasaini R, Thapa RB. 2014. Foraging behavior of different bee species under cage and open condition in Chitwan, Nepal. N Y Sci J 2014. 7:94-97

Richardson RT, Lin C, Sponsler DB, Quijia JO, Goodell K, Johnson RM. 2015. Application of ITS2 metabarcoding to determine the provenance of pollen collected by honey bees in an agroecosystem. Applications in Plant Sciences 3(1):1400066. doi: http://dx.doi.org/10.3732/apps.1400066

Rinkevich FD, Margotta JW, Pittman JM, Danka, R. G., Tarver, M. R., Ottea, J. A., \& Healy, K. B. 2015. Genetics, synergists, and age affect insecticide sensitivity of the honey bee, Apis mellifera. Rueppell O, ed. PLoS ONE 10(10): e0139841. doi:10.1371/journal.pone.0139841. 
Rueppell O, Bachelier C, Fondrk MK, Page RE, Jr. 2007. Regulation of life history determines lifespan of worker honey bees (Apis mellifera L.). ExpGerontol. 42:1020-1032.

Seeley TD. 1989. Social foraging in honey bees: how nectar foragers assess their colony's nutritional status. Behav Ecol Sociobiol. 24:181-199.

Seeley TD, Visscher PK. 1985. Survival of honey bees in cold climates: the critical timing of colony growth and reproduction. Ecol Entom.10: 81-88. doi: 10.1111/j.13652311.1985.tb00537.x

Siegel AJ, Freedman C, Page RE. 2012. Ovarian control of nectar collection in the honey bee (Apis mellifera). PLoS ONE 7(4). e33465. DOI:10.1371/journal.pone.0033465.

Sponsler DB, Johnson RM. 2015. Honey bee success predicted by landscape composition in Ohio, USA. PeerJ., 3:e838 DOI $10.7717 /$ peerj.838

Tan K, Yang S, Wang Z, RadloffSE, Oldroyd BP. 2012. Differences in foraging and broodnest temperature in the honey bees Apis cerana and A. mellifera. Apidologie 43, 618-623.
Toth AL, Kantarovich S, Meisel AF, Robinson GE. 2005. Nutritional status influences socially regulated foraging ontogeny in honey bees. J Exper Biol 208: 46414649; doi: 10.1242/jeb.01956

United States Department of Agriculture Agricultural Research Service. 2012. Colony Collapse Disorder: 2012 Annual Progress Report. Retrieved from https://www.ars.usda.gov/ is/br/ccd/ccdprogressreport2012.pdf

vanEngelsdorp D, Hayes Jr J, Underwood RM, Caron D, Pettis, J. 2011. A survey of managed honey bee colony losses in the USA, fall 2009 to winter 2010. J Apicult Resh 50(1): 1-10. doi:10.3896/IBRA.1.50.1.01

Weidenmüller A, Tautz J. 2002. In-hive behavior of pollen foragers (Apis mellifera) in honey bee colonies under conditions of high and low pollen need. Ethology. 108:205-221. 